OPEN ACCESS

Edited by:

M-Alain Babi,

Duke University, USA

Reviewed by:

Ahmed Hassan,

University of Illinois at Chicago, USA

Shyam Prabhakaran,

Northwestern University, USA

*Correspondence:

Michel T. Torbey

michel.torbey@osumc.edu

Specialty section:

This article was submitted to Neurocritical and Neurohospitalist

Care,

a section of the journal

Frontiers in Neurology

Received: 19 June 2016 Accepted: 24 February 2017

Published: 15 March 2017

Citation:

Gulati D, Dua D and Torbey MT (2017) Hemostasis in Intracranial Hemorrhage.

Front. Neurol. 8:80.

doi: 10.3389/fneur.2017.00080

\section{Hemostasis in Intracranial Hemorrhage}

\author{
Deepak Gulati, Dharti Dua and Michel T. Torbey*
}

Neurology Department, The Ohio State University College of Medicine, Columbus, OH, USA

Spontaneous non-traumatic intracerebral hemorrhage $(\mathrm{ICH})$ is associated with high morbidity and mortality throughout the world with no proven effective treatment. Majority of hematoma expansion occur within $4 \mathrm{~h}$ after symptom onset and is associated with early deterioration and poor clinical outcome. There is a vital role of ultra-early hemostatic therapy in $\mathrm{ICH}$ to limit hematoma expansion. Patients at risk for hematoma expansion are with underlying hemostatic abnormalities. Treatment strategy should include appropriate intervention based on the history of use of antithrombotic use or an underlying coagulopathy in patients with $\mathrm{ICH}$. For antiplatelet-associated $\mathrm{ICH}$, recommendation is to discontinue antiplatelet agent and transfuse platelets to those who will undergo neurosurgical procedure with moderate quality of evidence. For vitamin $\mathrm{K}$ antagonist-associated $\mathrm{ICH}$, administration of 3-factor or 4-factor prothrombin complex concentrates (PCCs) rather than fresh frozen plasma to patients with INR $>1.4$ is strongly recommended. For patients with novel oral anticoagulant-associated $\mathrm{ICH}$, administering activated charcoal to those who present within $2 \mathrm{~h}$ of ingestion is recommended. Idarucizumab, a humanized monoclonal antibody fragment against dabigatran (direct thrombin inhibitor) is approved by FDA for emergency situations. Administer activated PCC $(50 \mathrm{U} / \mathrm{kg})$ or 4-factor PCC $(50 \mathrm{U} / \mathrm{kg})$ to patients with $\mathrm{ICH}$ associated with direct thrombin inhibitors (DTI) if idarucizumab is not available or if the hemorrhage is associated with a DTI other than dabigatran. For factor Xa inhibitor-associated $\mathrm{ICH}$, administration of 4-factor PCC or aPCC is preferred over recombinant FVIla because of the lower risk of adverse thrombotic events.

Keywords: intracerebral hemorrhage, anticoagulants, new oral anticoagulants, reversal of anticoagulation, hemostasis

Spontaneous non-traumatic intracerebral hemorrhage (ICH) is associated with high morbidity and mortality throughout the world with no proven effective treatment (1). Of the nearly 40,000 Americans who experienced an ICH in 1997, 35-52\% were dead within 1 month and only $20 \%$ were living independently at 6 months (2). Although the incidence of ICH decreased over the past decade, case fatality and long-term morbidity remained unchanged with reported 30-day ICH mortality ranging from 30 to $50 \%(3,4)$.

\section{EARLY HEMATOMA GROWTH}

Hematoma expansion and early deterioration are common within the first few hours after ICH onset (4). Majority of hematoma expansion occur within $4 \mathrm{~h}$ after symptom onset, whereas an additional $12 \%$ of patients developed hematoma growth within the next $21 \mathrm{~h}(5)$. Early hematoma expansion is reported in $19-38 \%$ of patients with ICH and is associated with early deterioration and poor clinical outcome (5-7). 
Hematoma growth is seen as a crucial and independent determinant of both mortality and functional outcome after $\mathrm{ICH}$. For each $10 \%$ increase in hematoma growth, there is a $5 \%$ increased hazard of death, a $16 \%$ greater likelihood of worsening by one point on the mRS, or $18 \%$ of moving from independence to assisted independence or from assisted independence to poor outcome on the Barthel Index (8). Early hematoma growth has gained a lot of attention as an important cause of early neurological deterioration after ICH and has been thought to be a therapeutic target in many ongoing trials.

\section{RATIONALE FOR ULTRA-EARLY HEMOSTATIC THERAPY FOR ICH}

The three most important and consistent predictors of poor outcome after ICH are hematoma volume, presence of intraventricular hemorrhage, and depressed level of consciousness (9-12). Of these, hematoma volume is the single most powerful predictor of 30-day mortality after ICH (12). As bleeding can possibly continue for several hours, it is possible that ultra-early hemostatic therapy may be useful.

In order to even conceive any therapeutic benefit, hemostatic therapy should be given as soon as possible given that hematoma expansion is expected in 10,17 , or $22 \%$ of patients after a 15 , 30 , or 45-min treatment delay following the baseline scan (13). Although the challenges of stroke treatment within a narrow time window are well established, the feasibility of this approach is supported by the fact that $\mathrm{ICH}$ patients present to emergency departments earlier than ischemic stroke patients (14).

\section{HEMOSTATIC THERAPEUTIC APPROACH}

Patients at risk for ICH are with underlying hemostatic abnormalities, which include those taking oral anticoagulant drugs, antiplatelet agents, those with acquired or congenital coagulation factor deficiencies, and those with inherited or acquired qualitative or quantitative platelet abnormalities. Treatment strategy should include appropriate intervention based on the history of use of antithrombotic use or an underlying coagulopathy in patients with $\mathrm{ICH}$.

\section{Platelet-Related ICH}

More than $25 \%$ of patients presenting with ICH are taking antiplatelet therapy (15). Observational studies suggest that antiplatelet use before ICH might worsens the outcome by increasing the risk of early hematoma growth (16). Patients taking antiplatelet therapy beforehand have a $27 \%$ increased odds of death compared with those not taking antithrombotic drugs (17).

Platelet transfusion is potentially beneficial and used prophylactically in many clinical settings. Observational studies have shown variable association with outcome after platelet transfusion for acute ICH in patients taking antiplatelet therapy (18-20). The effect of platelet transfusion on ICH patients was studied in a recent randomized open label phase 3 trial, Platelet Transfusion versus Standard Care after acute stroke due to spontaneous ICH associated with antiplatelet therapy (PATCH). The study concluded that platelet transfusion was inferior to standard of care for patients taking antiplatelet therapy before ICH (21). The odds of death and dependence at 3 months were higher in the platelet transfusion group (OR 2.05; 95\% CI 1.18-3.56) (21). Forty-two percent of participants who received antiplatelet therapy had a serious adverse event during their hospital stay. After the findings of the PATCH trial, platelet transfusion cannot be recommended for the treatment of $\mathrm{ICH}$ in patients taking antiplatelet therapy (21). It is important though to keep in mind that most of the participants in PATCH had taken aspirin and relatively few had taken ADP inhibitors (21).

PATCH recent results appear to be contradictory to an earlier randomized trial of platelet transfusion in patients with $\mathrm{ICH}(22)$. This prospective, double-blind, parallel, randomized, controlled trial enrolled patients with acute hypertensive basal ganglia hemorrhages undergoing craniotomy and hematoma evacuation. In patients who received platelets, there was less ICH recurrence (14 versus $35 \%, P=0.02$ ) and lower postoperative hematoma volume in treated groups versus the untreated group. Additionally, those who received platelets had a significant reduction in mortality compared to those who did not (15.5 versus $34.2 \%, P=0.02$ ). Patients who were aspirin-resistant at baseline and did not receive transfusion had similar outcomes to aspirin-naive patients and better outcomes than aspirin-sensitive patients who did not receive a platelet transfusion. Platelet transfusion carries significant risks with limited benefit in ICH patients (23). Desmopressin (DDAVP) may be an attractive alternative.

DDAVP is an analog of vasopressin. It increases the endothelial release of large factor VIII: von Willebrand factor multimers and may also increase platelet membrane glycoprotein expression, promoting platelet adhesion to the endothelium (24-26). DDAVP has been shown to reduce bleeding time (27) and improved platelet function (as measured by collagen/epinephrine-closure time) (28) following DDAVP administration in uremic patients exposed to aspirin. DDAVP for antiplatelet reversal have been reported in one study (29). Patients with either history of aspirin use or reduced platelet activity received DDAVP $0.4 \mu \mathrm{g} / \mathrm{Kg}$ IV. In this study, DDAVP was well tolerated and improved platelet activity and low rate of hematoma growth after ICH (29). Table 1 summarizes the Neurocritical Care Society recommendation for antiplatelet agent reversal (30).

\section{Vitamin K-Related ICH}

The use of antithrombotic agents has increased over the last decade and is expected to continue to rise over the ensuing decades (31). Vitamin K antagonists (VKAs) are the most common treatments for secondary stroke prevention for patients with atrial fibrillation. Antithrombotic-associated-ICH comprises $12-20 \%$ of patients with $\mathrm{ICH}(32,33)$. Intracerebral hemorrhage accounts for the vast majority (90\%) of all VKA-related deaths (34). The rate of taking OACs has increased with the aging population and increased use of anticoagulant drugs in recent decades (31, 35). Most ICH related to VKA use occur with international normalizing ratios (INRs) in the recommended therapeutic range, although the risk of hemorrhage is further increased with progressive elevations of the INR (36-38). Urgent reversal of anticoagulation may improve outcomes, reduce mortality, and limit hematoma expansion (39-41). 


\section{TABLE 1 | Guidelines for antiplatelet agent reversal.}

(1) Recommend discontinuing antiplatelet agents when in intracerebra hemorrhage $(\mathrm{ICH})$ patients (good practice statement)

(2) Suggest against platelet transfusion for patients with antiplateletassociated $\mathrm{ICH}$ who will not undergo a neurosurgical procedure (conditional recommendation, low-quality evidence)

(3) Suggest platelet transfusion for patients with aspirin- or ADP inhibitorassociated intracranial hemorrhage who will undergo a neurosurgical procedure (conditional recommendation, moderate quality of evidence)

a. Recommend platelet function testing prior to platelet transfusion if possible (strong recommendation, moderate quality evidence)

b. When platelet function testing is not readily available, empiric platelet transfusion may be reasonable (conditional recommendation, low-quality evidence)

c. Recommend against platelet transfusion for patients with normal platelet function (strong recommendation, moderate quality evidence)

(4) Suggest an initial dose of one single-donor apheresis unit of platelets. Platelet testing is suggested prior to repeat platelet transfusion (conditional recommendation, moderate quality evidence)

(5) Suggest consideration of a single dose of desmopressin (DDAVP) in ICH (0.4 mcg/kg IV) associated with aspirin/COX-1 inhibitors or ADP receptor inhibitors (conditional recommendation, low-quality evidence)

Several effective treatment options are available for the reversal of VKAs, including vitamin $\mathrm{K}$, fresh frozen plasma (FFP), factor concentrates, and activated factors. FFP, along with vitamin $\mathrm{K}$, has been the mainstay of treatment in U.S. for years, but more recently, prothrombin complex concentrates (PCCs), activated PCC (aPCC) factor VII inhibitor bypassing activity (FEIBA), and recombinant activated factor VIIa (rVIIa) have emerged as potential therapies.

\section{Vitamin K}

It normalizes the INR by providing the necessary substrate to synthesize necessary clotting factors. Since it takes vitamin K several hours to be effective, it should never be used alone in the emergent treatment of ICH (42). It is important to administer vitamin $\mathrm{K}$ as an adjunctive therapy given its long half-life. Higher doses (5-10 mg) of vitamin K reverse INR more quickly than lower doses (43-46). Although this has not been well studied by given the fast rate of hematoma expansion in the first few hours after ICH, a large single dose of vitamin $\mathrm{K}$ is preferred to divided dosing (47). Vitamin $\mathrm{K}$ is more effective at INR reversal when administered IV as compared to similar dose administered subcutaneously (43, 44). Although oral and IV administration of vitamin K are equally effective in INR reversal, reversal is faster via the IV route $(43,45)$. The infusion should be administered slowly due to the low risk of anaphylaxis $(0.03 \%)$; however, the benefit of faster infusion and INR reversal justifies the risk $(48,49)$.

Fresh frozen plasma directly replaces the clotting factors. Although the data regarding its use in ICH are mixed, it is commonly administered with vitamin K (50-54). Given the delay needed to prepare FFP makes its use in acute ICH very limited. Goldstein et al. observed that for every $30 \mathrm{~min}$ of delay in the first dose of FFP, the odds of INR reversal within $24 \mathrm{~h}$ was decreased by $20 \%$ (53). Furthermore, urgent INR reduction was only achieved in $9.6 \%$ of patient receiving FFP (55).

Prothrombin complex concentrates are biologically inactivated, vitamin-K-dependent coagulation factors prepared from pooled plasma agents that are lyophilized and can be quickly reconstituted and administered to patients. The first 4-factor PCC (Kcentra, CSL Behring, King of Prussia, PA, USA), containing coagulation factors II, VII, IX, and X, as well as proteins $\mathrm{C}$ and $\mathrm{S}$, received FDA approval in 2013 for reversal of coagulopathy from oral VKA therapy in adults with acute major bleeding and those patients requiring urgent surgery or interventional procedures.

The advantages with PCC are no need for cross matching, reconstituted and administered rapidly in a small volume, and does not transmit infectious agents. The disadvantages of FFP are the requirement of thawing and cross matching, allergic and infectious transfusion reactions, large volumes, and unable to achieve rapid correction of $\operatorname{INR}(53,56)$. PCCs rapidly normalize the INR (within minutes) in patients taking warfarin (57-59). The rate of achieving an INR $<1.3$ within 30 min of completing therapy was $62.2 \%$ for PCC and $9.6 \%$ for FFP with similar thromboembolic events and fluid overload being more common with FFP (55). PCCs may increase the risk of thrombotic complications, although the risk appears low (57).

There is currently no trial to evaluate 3-factor and 4-factor PCCs against each other. In the international multicenter registry of over 1,500 ICH patients, patients treated with 3-factor PCC demonstrated improved case-fatality compared with those treated with 4 -factor PCC (60). The target INR ranges from $<1.3$ to $<1.5$ has been cited in various studies (61). A large multinational observational study of VKA-ICH reversal demonstrated no significant differences in the case fatality ratios for patients treated with FFP compared with PCC (60). Several small studies have shown increase survival and reduced hematoma expansion with PCC $(39,41,62,63)$.

The INR Normalization in Coumadin Associated Intracerebral Hemorrhage (INCH) trial, a randomized controlled trial of PCC compared with FFP, was stopped prematurely due to clear benefit of PCC. Results showed that 4-factor-PCC is superior to FFP in normalizing the INR within $3 \mathrm{~h}$ in patients with VKA-related ICH (64).

Recombinant FVIIa (rFVIIa) has been shown to correct the INR more rapidly than FFP (65). rFVIIa is not currently recommended for routine use in warfarin reversal. Two large randomized trials evaluated the use of rFVIIa in ICH $(66,67)$. Although both trials showed that rFVIIa was able to limit hematoma expansion, the phase III trial failed to demonstrate a benefit in functional outcome or mortality with significantly more thrombotic events as compared to placebo (9 versus $4 \%)(66,67)$. Limited data exist comparing PCC to rFVIIa. Current guidelines recommend against the routine use of rFVIIa alone for the reversal of VKAs (30). Table 2 summarizes the NCS recommendations for VKA reversal (30).

\section{NEW ANTICOAGULANT MEDICATION- RELATED ICH}

New oral anticoagulants (NOACs) including direct thrombin inhibitors (DTIs) and factor Xa inhibitors (FXa-Is) have been recently approved for primary and secondary prophylaxis of thromboembolic conditions. The use of NOAC for systemic anticoagulation has increased dramatically due to their putative advantages versus warfarin, rapidly growing proportion of 
(1) Discontinue VKAs when $\mathrm{ICH}$ is present or suspected (good practice statement)

(2) Urgent reversal of VKAs in patients with ICH with the following exceptions (strong recommendation, moderate quality evidence)

a. High suspicion of $\mathrm{ICH}$ due to cerebral venous thrombosis (conditional recommendation, very low-quality evidence)

b. In patients with concurrent symptomatic or life-threatening thrombosis, ischemia, heparin-induced thrombocytopenia, or DIC (good practice statement)

(3) Administration of vitamin $\mathrm{K}$ as soon as possible or concomitantly with other reversal agents (strong recommendation, moderate quality evidence). The following

dosing is recommended:

a. One dose of vitamin $\mathrm{K} 10 \mathrm{mg} \mathrm{IV}$

b. Subsequent treatment should be guided by follow-up international normalizing ratios (INRs) (good practice statement)

c. If repeat INR is still elevated C 1.4 within the first $24-48 \mathrm{~h}$ after reversal agent administration, redose with vitamin $\mathrm{K} 10 \mathrm{mg}$ IV (good practice statement)

(4) Administer 3-factor or 4-factor prothrombin complex concentrates (PCCs) rather than fresh frozen plasma (FFP) to patients with INR >1.4 (strong recommendation,

moderate quality evidence)

a. 4-factor PCC is preferred over 3-factor PCC (conditional recommendation, low-quality evidence)

b. Suggest initial reversal with PCC alone rather than combined with FFP or recombinant FVIla (rFVIla) (conditional recommendation, low-quality evidence)

c. PCC dosing should be weight-based and vary according to admission INR and type of PCC used (strong recommendation, moderate quality evidence)

d. INR testing should be repeated soon after PCC administration (15-60 min), and serially every 6-8 h for the next 24-48 h.

e. Subsequent treatment should be guided by follow-up INR.

f. Repeat PCC dosing may lead to increased thrombotic complications and risk of DIC.

g. If repeat INR is still elevated $>1.4$ within the first $24-48 \mathrm{~h}$ after initial PCC dosing, suggest further correction with FFP.

(5) Recommend against administration of rFVlla for the reversal of VKA (strong recommendation, low quality evidence)

(6) If PCCs are not available or contraindicated, alternative treatment is recommended over no treatment (strong recommendation, moderate quality evidence)

a. Treatment with FFP and vitamin $\mathrm{K}$ is recommended over no treatment (strong recommendation, moderate quality evidence)

b. Suggest dosing FFP at 10-15 ml/kg IV along with one dose of vitamin K $10 \mathrm{mg}$ IV (conditional recommendation, low-quality evidence)

elderly Americans, and the expanding indications for NOAC medications. NOAC have a shorter half-life $(5-15 \mathrm{~h})$, fewer food and drug interactions, fixed dosing, no need for frequent blood monitoring, and a rapid and reliable duration to onset and offset (68).

Direct thrombin inhibitors carry less risk of ICH (69). In the Randomized Evaluation of Long-Term Anticoagulant Therapy (Re-Ly) trial, dabigatran had a $0.31 \%$ risk of ICH compared to $0.76 \%$ with warfarin (70). NOAC were associated with a $47 \%$ odds reduction in the risk of fatal bleeding in one of the metaanalysis of 11 randomized controlled trials compared to vitamin K use (71).

Although animal models have shown some benefit of PCC in reversing the effect of dabigatran $(72,73)$, a randomized trial of healthy volunteers failed to shown an effect of PCC on aPTT, ecarin clotting time (ECT), and thrombin time (TT) (74). On the basis of in vitro and preclinical data, administration of aPCC is preferred over 4-factor PCC for patients receiving dabigatran (75).

Idarucizumab, a humanized monoclonal antibody fragment against dabigatran, completely reversed the anticoagulant activity of dabigatran in $88-98 \%$ of patients (76). In a prospective cohort of 90 patients receiving dabigatran who required urgent reversal, $5 \mathrm{~g}$ of IV idarucizumab normalized the dilute TT and ECT in $88-98 \%$ of patients within minutes. There was one reported thrombotic event within $72 \mathrm{~h}$ of administration of the drug. In October 2015, U.S. FDA granted accelerated approval to Praxbind (idarucizumab) for use in patients who are taking the anticoagulant Pradaxa (dabigatran) during emergency situations when there is a need to reverse Pradaxa's blood-thinning effects.

\section{Direct FXa-I}

The risk of ICH for FXa-I is lower than warfarin (69). In ROCKET-AF (An Efficacy and Safety Study of Rivaroxaban with Warfarin for the Prevention of Stroke and Non-Central Nervous
System Systemic Embolism in Patients with Non-Valvular Atrial Fibrillation) trial, rivaroxaban had $0.5 \%$ risk of ICH compared to $0.7 \%$ with warfarin (77). Similarly, in ARISTOTLE (Apixaban for the Prevention of Stroke in Subjects with Atrial Fibrillation) trial, apixaban had a $0.33 \%$ risk of ICH compared with $0.8 \%$ with warfarin (78).

Animal studies and limited clinical data suggest that 4 -factor PCC is better for patients with refractory rivaroxaban- or apixaban-associated hemorrhage due to high concentrations of factor X contained within $(79,80)$. One retrospective study reported the use of 4-factor PCC to reverse coagulopathy secondary to rivaroxaban and apixaban in the setting of ICH (80).

Andexanet alfa is a recombinant human protein (modified FXa protein) that binds and inactivates FXa inhibitors. It has been studied with rivaroxaban, apixaban, and low-molecular-weight heparin (81). Infusion of andexanet alfa was able to quickly normalize several laboratory assays in randomized controlled trials of healthy elderly volunteers (82). However, it may require prolonged infusion because anti-FXa activity returned after stopping the infusion. Andexanet has no known hemostatic effects. It did reduce tissue factor pathway inhibitor levels, which may imply a prothrombotic effect (81). The ANNEXA-4 trial demonstrated that an initial bolus and subsequent 2-h infusion of andexanet substantially reduced anti-factor Xa activity in patients with acute major bleeding associated with FXa-I, with effective hemostasis occurring in $79 \%$ (83).

Ciraparantag, a synthetic water-soluble compound, binds directly to unfractionated and low-molecular weight heparin. It serves as a potential universal antidote for several different classes of anticoagulant drugs. The synthetic compound ciraparantag may prove to be an effective universal reversal agent. It was able to reduce bleeding in animal models and normalize coagulation assays in healthy volunteers given edoxaban and dabigatran with a single IV dose $(81,84)$. Results of further studies and review by the FDA are pending. 


\section{TABLE 3 | Guidelines for reversal of new oral anticoagulants.}

\section{Direct factor Xa inhibitors (FXa-Is)}

(1) Discontinue FXa-I when $\mathrm{ICH}$ is present or suspected (good practice statement)

(2) Pharmacological reversal of oral FXa-I should be guided primarily by bleeding (major or intracranial) and not primarily by laboratory testing (conditional recommendation, low-quality evidence)

(3) Suggest administration of activated charcoal $(50 \mathrm{~g})$ to intubated $\mathrm{ICH}$ patients with enteral access and/or those at low risk of aspiration who present within $2 \mathrm{~h}$ of ingestion of an oral direct factor Xa inhibitor (conditional recommendation, very low-quality evidence)

(4) Suggest administering a 4-factor prothrombin complex concentrate (PCC) (50 U/kg) or activated PCC (aPCC) (50 U/kg) if ICH occurred within 3-5 terminal half-lives of drug exposure or in the context of liver failure (conditional recommendation, low-quality evidence)

(5) Suggest administering 4-factor PCC or aPCC over recombinant FVIla (rFVIla) because of the lower risk of adverse thrombotic events (conditional recommendation, low-quality evidence)

\section{Direct thrombin inhibitors (DTIs)}

(1) Discontinue DTI when ICH is present or suspected (good practice statement)

(2) Pharmacological reversal of DTI should be guided primarily by bleeding (major or intracranial) and not primarily by laboratory testing (conditional recommendation, low-quality evidence)

(3) Suggest administering activated charcoal (50 g) to intubated intracranial hemorrhage patients with enteral access and/or those at low risk of aspiration who present within $2 \mathrm{~h}$ of ingestion of an oral direct thrombin inhibitor (conditional recommendation, very low-quality evidence)

(4) Recommend administering idarucizumab (5 g IV in two divided doses) to patients with ICH associated with dabigatran if dabigatran was administered: a. Within a period of 3-5 half-lives and there is no evidence of renal failure (strong recommendation, moderate quality of evidence) or

b. There is renal insufficiency leading to continued drug exposure beyond the normal 3-5 half-lives (strong recommendation, moderate quality of evidence)

(5) Suggest administering aPCC $(50 \mathrm{U} / \mathrm{kg})$ or 4-factor PCC $(50 \mathrm{U} / \mathrm{kg})$ to patients with $\mathrm{ICH}$ associated with DTI if idarucizumab is not available or if the hemorrhage is associated with a DTI other than dabigatran

(6) In patients with dabigatran-associated $\mathrm{ICH}$ and renal insufficiency or dabigatran overdose, suggest hemodialysis if idarucizumab is not available (conditional recommendation, low-quality data)

(7) In patients with dabigatran-associated ICH who have already been treated with idarucizumab, PCC, or aPCC, with ongoing evidence of clinically significant bleeding, we suggest consideration of redosing idarucizumab and/or hemodialysis (Conditional recommendation, low-quality evidence)

(8) Recommend against administration of rFVIla or FFP in direct thrombin inhibitor-related intracranial hemorrhage (strong recommendation, low-quality evidence)

If oral drug intake was within a couple hours of presentation, oral activated charcoal offers a low side effect treatment option for NOAC (85). However, caution should be exhibited given the risk of aspiration and potential elevated intracranial pressure induced by vomiting. Hemodialysis should also be considered. Hemodialysis is more effective with dabigatran and less so for rivaroxaban or apixaban because they are more highly protein bound (85). Table 3 summarizes the NCS guidelines for reversal of NOAC (30).

\section{CONCLUSION}

Intracerebral hemorrhage is a devastating disease associated with high morbidity and mortality. Although no clinical trials have clearly showed the benefit of prompt reversal of coagulation

\section{REFERENCES}

1. Go AS, Mozaffarian D, Roger VL, Benjamin EJ, Berry JD, Borden WB, et al. Heart disease and stroke statistics - 2013 update: a report from the American Heart Association. Circulation (2013) 127(1):e6-245. doi:10.1161/ CIR.0b013e318282ab8f

2. Broderick JP, Adams HP Jr, Barsan W, Feinberg W, Feldmann E, Grotta J, et al. Guidelines for the management of spontaneous intracerebral hemorrhage: a statement for healthcare professionals from a special writing group of the stroke council, American Heart Association. Stroke (1999) 30(4):905-15. doi:10.1161/01.STR.30.4.905

3. Zahuranec DB, Lisabeth LD, Sánchez BN, Smith MA, Brown DL, Garcia $\mathrm{NM}$, et al. Intracerebral hemorrhage mortality is not changing despite declining incidence. Neurology (2014) 82(24):2180-6. doi:10.1212/ WNL.0000000000000519 abnormalities, it is a good practice to correct these abnormalities as fast as possible until further data are available.

\section{AUTHOR CONTRIBUTIONS}

DG and DD worked on the literature search and prepared the initial draft of the manuscript. MT reviewed the literature and edited the manuscript significantly. DG and MT finalized the manuscript.

\section{FUNDING}

This work has been partly funded by NINDS award \# 4U10NS086484-04.

4. Li Q, Zhang G, Xiong X, Wang XC, Yang WS, Li KW, et al. Black hole sign: novel imaging marker that predicts hematoma growth in patients with intracerebral hemorrhage. Stroke (2016) 47(7):1777-81. doi:10.1161/ STROKEAHA.116.013186

5. Brott T, Broderick J, Kothari R, Barsan W, Tomsick T, Sauerbeck L, et al. Early hemorrhage growth in patients with intracerebral hemorrhage. Stroke (1997) 28(1):1-5. doi:10.1161/01.STR.28.1.1

6. Fujii Y, Tanaka R, Takeuchi S, Koike T, Minakawa T, Sasaki O. Hematoma enlargement in spontaneous intracerebral hemorrhage. J Neurosurg (1994) 80(1):51-7. doi:10.3171/jns.1994.80.1.0051

7. Li Q, Huang YJ, Zhang G, Lv FJ, Wei X, Dong MX, et al. Intraventricular hemorrhage and early hematoma expansion in patients with intracerebral hemorrhage. Sci Rep (2015) 5:11357. doi:10.1038/srep11357

8. Davis SM, Broderick J, Hennerici M, Brun NC, Diringer MN, Mayer SA, et al. Hematoma growth is a determinant of mortality and poor outcome after 
intracerebral hemorrhage. Neurology (2006) 66(8):1175-81. doi:10.1212/ 01.wnl.0000208408.98482.99

9. Tuhrim S, Dambrosia JM, Price TR, Mohr JP, Wolf PA, Hier DB, et al. Intracerebral hemorrhage: external validation and extension of a model for prediction of 30-day survival. Ann Neurol (1991) 29(6):658-63. doi:10.1002/ ana.410290614

10. Portenoy RK, Lipton RB, Berger AR, Lesser ML, Lantos G. Intracerebral haemorrhage: a model for the prediction of outcome. J Neurol Neurosurg Psychiatry (1987) 50(8):976-9. doi:10.1136/jnnp.50.8.976

11. Daverat P, Castel JP, Dartigues JF, Orgogozo JM. Death and functional outcome after spontaneous intracerebral hemorrhage. A prospective study of 166 cases using multivariate analysis. Stroke (1991) 22(1):1-6. doi:10.1161/ 01.STR.22.1.1

12. Broderick JP, Brott TG, Duldner JE, Tomsick T, Huster G. Volume of intracerebral hemorrhage. A powerful and easy-to-use predictor of 30-day mortality. Stroke (1993) 24(7):987-93. doi:10.1161/01.STR.24.7.987

13. Mayer SA. Ultra-early hemostatic therapy for intracerebral hemorrhage. Stroke (2002) 34(1):224-9. doi:10.1161/01.STR.0000046458.67968.E4

14. Alberts MJ, Bertels C, Dawson DV. An analysis of time of presentation after stroke. JAMA (1990) 263(1):65-8. doi:10.1001/jama.1990.03440010063031

15. Lovelock CE, Molyneux AJ, Rothwell PM; Oxford Vascular Study. Change in incidence and aetiology of intracerebral haemorrhage in Oxfordshire, UK, between 1981 and 2006: a population-based study. Lancet Neurol (2007) 6(6):487-93. doi:10.1016/S1474-4422(07)70107-2

16. Naidech AM, Jovanovic B, Liebling S, Garg RK, Bassin SL, Bendok BR, et al. Reduced platelet activity is associated with early clot growth and worse 3-month outcome after intracerebral hemorrhage. Stroke (2009) 40(7):2398401. doi:10.1161/STROKEAHA.109.550939

17. Thompson BB, Béjot Y, Caso V, Castillo J, Christensen H, Flaherty ML, et al. Prior antiplatelet therapy and outcome following intracerebral hemorrhage: a systematic review. Neurology (2010) 75(15):1333-42. doi:10.1212/ WNL.0b013e3181f735e5

18. Creutzfeldt CJ, Weinstein JR, Longstreth WT Jr, Becker KJ, McPharlin TO, Tirschwell DL. Prior antiplatelet therapy, platelet infusion therapy, and outcome after intracerebral hemorrhage. J Stroke Cerebrovasc Dis (2009) 18(3):221-8. doi:10.1016/j.jstrokecerebrovasdis.2008.10.007

19. Ducruet AF, Hickman ZL, Zacharia BE, Grobelny BT, DeRosa PA, Landes E, et al. Impact of platelet transfusion on hematoma expansion in patients receiving antiplatelet agents before intracerebral hemorrhage. Neurol Res (2010) 32(7):706-10. doi:10.1179/174313209X459129

20. Naidech AM, Liebling SM, Rosenberg NF, Lindholm PF, Bernstein RA, Batjer $\mathrm{HH}$, et al. Early platelet transfusion improves platelet activity and may improve outcomes after intracerebral hemorrhage. Neurocrit Care (2012) 16(1):82-7. doi:10.1007/s12028-011-9619-3

21. Baharoglu MI, Cordonnier C, Al-Shahi Salman R, de Gans K, Koopman MM, Brand A, et al. Platelet transfusion versus standard care after acute stroke due to spontaneous cerebral haemorrhage associated with antiplatelet therapy (PATCH): a randomised, open-label, phase 3 trial. Lancet (2016) 387(10038):2605-13. doi:10.1016/S0140-6736(16)30392-0

22. Li X, Sun Z, Zhao W, Zhang J, Chen J, Li Y, et al. Effect of acetylsalicylic acid usage and platelet transfusion on postoperative hemorrhage and activities of daily living in patients with acute intracerebral hemorrhage. J Neurosurg (2013) 118(1):94-103. doi:10.3171/2012.9.JNS112286

23. Morrow JF, Braine HG, Kickler TS, Ness PM, Dick JD, Fuller AK. Septic reactions to platelet transfusions. A persistent problem. JAMA (1991) 266(4):555-8. doi:10.1001/jama.1991.03470040119033

24. Zeigler ZR, Megaludis A, Fraley DS. Desmopressin (d-DAVP) effects on platelet rheology and von Willebrand factor activities in uremia. Am J Hematol (1992) 39(2):90-5. doi:10.1002/ajh.2830390204

25. Gordz S, Mrowietz C, Pindur G, Park JW, Jung F. Effect of desmopressin (DDAVP) on platelet membrane glycoprotein expression in patients with von Willebrand's disease. Clin Hemorheol Microcirc (2005) 32(2):83-7.

26. Calmer S, Ferkau A, Larmann J, Johanning K, Czaja E, Hagl C, et al. Desmopressin (DDAVP) improves recruitment of activated platelets to collagen but simultaneously increases platelet endothelial interactions in vitro. Platelets (2014) 25(1):8-15. doi:10.3109/09537104.2013.767442

27. Mannucci PM, Remuzzi G, Pusineri F, Lombardi R, Valsecchi C, Mecca G, et al. Deamino-8-D-arginine vasopressin shortens the bleeding time in uremia. N Engl J Med (1983) 308(1):8-12. doi:10.1056/NEJM198301063080102
28. Kim JH, Baek CH, Min JY, Kim JS, Kim SB, Kim H. Desmopressin improves platelet function in uremic patients taking antiplatelet agents who require emergent invasive procedures. Ann Hematol (2015) 94(9):1457-61. doi:10.1007/s00277-015-2384-1

29. Naidech AM, Maas MB, Levasseur-Franklin KE, Liotta EM, Guth JC, Berman $\mathrm{M}$, et al. Desmopressin improves platelet activity in acute intracerebral hemorrhage. Stroke (2014) 45(8):2451-3. doi:10.1161/STROKEAHA.114. 006061

30. Frontera JA, Lewin JJ III, Rabinstein AA, Aisiku IP, Alexandrov AW, Cook $\mathrm{AM}$, et al. Guideline for reversal of antithrombotics in intracranial hemorrhage: a statement for healthcare professionals from the neurocritical care society and society of critical care medicine. Neurocrit Care (2016) 24(1):6-46. doi:10.1007/s12028-015-0222-x

31. Flaherty ML, Kissela B, Woo D, Kleindorfer D, Alwell K, Sekar P, et al. The increasing incidence of anticoagulant-associated intracerebral hemorrhage. Neurology (2007) 68(2):116-21. doi:10.1212/01.wnl.0000250340. $05202.8 \mathrm{~b}$

32. Cucchiara B, Messe S, Sansing L, Kasner S, Lyden P; CHANT Investigators. Hematoma growth in oral anticoagulant related intracerebral hemorrhage. Stroke (2008) 39(11):2993-6. doi:10.1161/STROKEAHA.108.520668

33. Béjot Y, Cordonnier C, Durier J, Aboa-Eboulé C, Rouaud O, Giroud M. Intracerebral haemorrhage profiles are changing: results from the Dijon population-based study. Brain (2013) 136(Pt 2):658-64. doi:10.1093/brain/ aws349

34. Fang MC, Go AS, Chang Y, Hylek EM, Henault LE, Jensvold NG, et al. Death and disability from warfarin-associated intracranial and extracranial hemorrhages. Am J Med (2007) 120(8):700-5. doi:10.1016/j.amjmed.2006. 07.034

35. Huhtakangas J, Tetri S, Juvela S, Saloheimo P, Bode MK, Hillbom M. Effect of increased warfarin use on warfarin-related cerebral hemorrhage: a longitudinal population-based study. Stroke (2011) 42(9):2431-5. doi:10.1161/ STROKEAHA.111.615260

36. Eckman MH, Rosand J, Knudsen KA, Singer DE, Greenberg SM. Can patients be anticoagulated after intracerebral hemorrhage? A decision analysis. Stroke (2003) 34(7):1710-6. doi:10.1161/01.STR.0000078311.18928.16

37. Neau JP, Couderq C, Ingrand P, Blanchon P, Gil R; VGP Study Group. Intracranial hemorrhage and oral anticoagulant treatment. Cerebrovasc Dis (2001) 11(3):195-200. doi:10.1159/000047638

38. Punthakee X, Doobay J, Anand SS. Oral-anticoagulant-related intracerebral hemorrhage. Thromb Res (2002) 108(1):31-6. doi:10.1016/ S0049-3848(02)00398-5

39. Huttner HB, Schellinger PD, Hartmann M, Köhrmann M, Juettler E, Wikner $\mathrm{J}$, et al. Hematoma growth and outcome in treated neurocritical care patients with intracerebral hemorrhage related to oral anticoagulant therapy: comparison of acute treatment strategies using vitamin $\mathrm{K}$, fresh frozen plasma, and prothrombin complex concentrates. Stroke (2006) 37(6):1465-70. doi:10.1161/01.STR.0000221786.81354.d6

40. Kuramatsu JB, Gerner ST, Schellinger PD, Glahn J, Endres M, Sobesky J, et al. Anticoagulant reversal, blood pressure levels, and anticoagulant resumption in patients with anticoagulation-related intracerebral hemorrhage. JAMA (2015) 313(8):824-36. doi:10.1001/jama.2015.0846

41. Hanger HC, Geddes JA, Wilkinson TJ, Lee M, Baker AE. Warfarin-related intracerebral haemorrhage: better outcomes when reversal includes prothrombin complex concentrates. Intern Med J (2013) 43(3):308-16. doi:10.1111/imj.12034

42. Broderick J, Connolly S, Feldmann E, Hanley D, Kase C, Krieger D, et al. Guidelines for the management of spontaneous intracerebral hemorrhage in adults: 2007 update: a guideline from the American Heart Association/ American Stroke Association stroke council, high blood pressure research council, and the quality of care and outcomes in research interdisciplinary working group. Circulation (2007) 116(16):e391-413. doi:10.1161/ CIRCULATIONAHA.107.183689

43. Watson HG, Baglin T, Laidlaw SL, Makris M, Preston FE. A comparison of the efficacy and rate of response to oral and intravenous Vitamin $\mathrm{K}$ in reversal of over-anticoagulation with warfarin. Br J Haematol (2001) 115(1):145-9. doi:10.1046/j.1365-2141.2001.03070.x

44. Whitling AM, Bussey HI, Lyons RM. Comparing different routes and doses of phytonadione for reversing excessive anticoagulation. Arch Intern Med (1998) 158(19):2136-40. doi:10.1001/archinte.158.19.2136 
45. Nee R, Doppenschmidt D, Donovan DJ, Andrews TC. Intravenous versus subcutaneous vitamin $\mathrm{K} 1$ in reversing excessive oral anticoagulation. Am J Cardiol (1999) 83(2):286-8. doi:10.1016/S0002-9149(98)00842-X

46. Yasaka M, Sakata T, Minematsu K, Naritomi H. Correction of INR by prothrombin complex concentrate and vitamin $\mathrm{K}$ in patients with warfarin related hemorrhagic complication. Thromb Res (2002) 108(1):25-30. doi:10.1016/ S0049-3848(02)00402-4

47. Butler AC, Tait RC. Management of oral anticoagulant-induced intracranial haemorrhage. Blood Rev (1998) 12(1):35-44. doi:10.1016/ S0268-960X(98)90028-5

48. Choonara IA, Scott AK, Haynes BP, Cholerton S, Breckenridge AM, Park BK. Vitamin K1 metabolism in relation to pharmacodynamic response in anticoagulated patients. Br J Clin Pharmacol (1985) 20(6):643-8. doi:10.1111/ j.1365-2125.1985.tb05123.x

49. Riegert-Johnson DL, Volcheck GW. The incidence of anaphylaxis following intravenous phytonadione (vitamin K1): a 5-year retrospective review. Ann Allergy Asthma Immunol (2002) 89(4):400-6. doi:10.1016/ S1081-1206(10)62042-X

50. Fredriksson K, Norrving B, Stromblad LG. Emergency reversal of anticoagulation after intracerebral hemorrhage. Stroke (1992) 23(7):972-7. doi:10.1161/01.STR.23.7.972

51. Ivascu FA, Howells GA, Junn FS, Bair HA, Bendick PJ, Janczyk RJ. Rapid warfarin reversal in anticoagulated patients with traumatic intracranial hemorrhage reduces hemorrhage progression and mortality. J Trauma (2005) 59(5):1131-7; discussion 1137-9. doi:10.1097/01.ta.0000189067. 16368.83

52. Chapman SA, Irwin ED, Beal AL, Kulinski NM, Hutson KE, Thorson MA. Prothrombin complex concentrate versus standard therapies for INR reversal in trauma patients receiving warfarin. Ann Pharmacother (2011) 45(7-8):869-75. doi:10.1345/aph.1P605

53. Goldstein JN, Thomas SH, Frontiero V, Joseph A, Engel C, Snider R, et al. Timing of fresh frozen plasma administration and rapid correction of coagulopathy in warfarin-related intracerebral hemorrhage. Stroke (2006) 37(1):151-5. doi:10.1161/01.STR.0000195047.21562.23

54. Lee SB, Manno EM, Layton KF, Wijdicks EF. Progression of warfarin-associated intracerebral hemorrhage after INR normalization with FFP. Neurology (2006) 67(7):1272-4. doi:10.1212/01.wnl.0000238104.75563.2f

55. Sarode R, Milling TJ Jr, Refaai MA, Mangione A, Schneider A, Durn BL, et al. Efficacy and safety of a 4 -factor prothrombin complex concentrate in patients on vitamin $\mathrm{K}$ antagonists presenting with major bleeding: a randomized, plasma-controlled, phase IIIb study. Circulation (2013) 128(11):1234-43. doi:10.1161/CIRCULATIONAHA.113.002283

56. Boulis NM, Bobek MP, Schmaier A, Hoff JT. Use of factor IX complex in warfarin-related intracranial hemorrhage. Neurosurgery (1999) 45(5):1113-8; discussion. doi:10.1097/00006123-199911000-00020

57. Leissinger CA, Blatt PM, Hoots WK, Ewenstein B. Role of prothrombin complex concentrates in reversing warfarin anticoagulation: a review of the literature. Am J Hematol (2008) 83(2):137-43. doi:10.1002/ajh.21046

58. Pabinger I, Brenner B, Kalina U, Knaub S, Nagy A, Ostermann H, et al. Prothrombin complex concentrate (Beriplex $\mathrm{P} / \mathrm{N}$ ) for emergency anticoagulation reversal: a prospective multinational clinical trial. J Thromb Haemost (2008) 6(4):622-31. doi:10.1111/j.1538-7836.2008.02904.x

59. Riess HB, Meier-Hellmann A, Motsch J, Elias M, Kursten FW, Dempfle CE. Prothrombin complex concentrate (Octaplex) in patients requiring immediate reversal of oral anticoagulation. Thromb Res (2007) 121(1):9-16. doi:10.1016/j.thromres.2007.02.009

60. Parry-Jones AR, Di Napoli M, Goldstein JN, Schreuder FH, Tetri S, Tatlisumak $\mathrm{T}$, et al. Reversal strategies for vitamin $\mathrm{K}$ antagonists in acute intracerebral hemorrhage. Ann Neurol (2015) 78(1):54-62. doi:10.1002/ana.24416

61. Steiner T, Rosand J, Diringer M. Intracerebral hemorrhage associated with oral anticoagulant therapy: current practices and unresolved questions. Stroke (2006) 37:256-62. doi:10.1161/01.STR.0000196989.09900.f8

62. Frontera JA, Gordon E, Zach V, Jovine M, Uchino K, Hussain MS, et al. Reversal of coagulopathy using prothrombin complex concentrates is associated with improved outcome compared to fresh frozen plasma in warfarin-associated intracranial hemorrhage. Neurocrit Care (2014) 21(3):397-406. doi:10.1007/ s12028-014-9972-0

63. Majeed A, Meijer K, Larrazabal R, Arnberg F, Luijckx GJ, Roberts RS, et al. Mortality in vitamin $\mathrm{K}$ antagonist-related intracerebral bleeding treated with plasma or 4-factor prothrombin complex concentrate. Thromb Haemost (2014) 111(2):233-9. doi:10.1160/TH13-07-0536

64. Steiner T, Poli S, Griebe M, Hüsing J, Hajda J, Freiberger A, et al. Fresh frozen plasma versus prothrombin complex concentrate in patients with intracranial haemorrhage related to vitamin $\mathrm{K}$ antagonists ( $\mathrm{INCH}$ ): a randomised trial. Lancet Neurol (2016) 15(6):566-73. doi:10.1016/S1474-4422(16)00110-1

65. Freeman WD, Brott TG, Barrett KM, Castillo PR, Deen HG Jr, Czervionke LF, et al. Recombinant factor VIIa for rapid reversal of warfarin anticoagulation in acute intracranial hemorrhage. Mayo Clin Proc (2004) 79(12):1495-500. doi:10.4065/79.12.1495

66. Mayer SA, Brun NC, Begtrup K, Broderick J, Davis S, Diringer MN, et al. Efficacy and safety of recombinant activated factor VII for acute intracerebral hemorrhage. N Engl J Med (2008) 358(20):2127-37. doi:10.1056/ NEJMoa0707534

67. Mayer SA, Brun NC, Broderick J, Davis SM, Diringer MN, Skolnick BE, et al. Recombinant activated factor VII for acute intracerebral hemorrhage: US phase IIA trial. Neurocrit Care (2006) 4(3):206-14. doi:10.1385/ NCC:4:3:206

68. Le Roux P, Pollack CV Jr, Milan M, Schaefer A. Race against the clock: overcoming challenges in the management of anticoagulant-associated intracerebral hemorrhage. J Neurosurg (2014) 121(Suppl):1-20. doi:10.3171/2014.8.paradigm

69. Miller CS, Grandi SM, Shimony A, Filion KB, Eisenberg MJ. Meta-analysis of efficacy and safety of new oral anticoagulants (dabigatran, rivaroxaban, apixaban) versus warfarin in patients with atrial fibrillation. Am J Cardiol (2012) 110(3):453-60. doi:10.1016/j.amjcard.2012.03.049

70. Hart RG, Diener HC, Yang S, Connolly SJ, Wallentin L, Reilly PA, et al. Intracranial hemorrhage in atrial fibrillation patients during anticoagulation with warfarin or dabigatran: the RE-LY trial. Stroke (2012) 43(6):1511-7. doi:10.1161/STROKEAHA.112.650614

71. Caldeira D, Rodrigues FB, Barra M, Santos AT, de Abreu D, Gonçalves N, et al. Non-vitamin $\mathrm{K}$ antagonist oral anticoagulants and major bleeding-related fatality in patients with atrial fibrillation and venous thromboembolism: a systematic review and meta-analysis. Heart (2015) 101(15):1204-11. doi:10.1136/heartjnl-2015-307489

72. Illanes S, Zhou W, Schwarting S, Heiland S, Veltkamp R. Comparative effectiveness of hemostatic therapy in experimental warfarin-associated intracerebral hemorrhage. Stroke (2011) 42(1):191-5. doi:10.1161/ STROKEAHA.110.593541

73. van Ryn J, Stangier J, Haertter S, Liesenfeld KH, Wienen W, Feuring M, et al. Dabigatran etexilate - a novel, reversible, oral direct thrombin inhibitor: interpretation of coagulation assays and reversal of anticoagulant activity. Thromb Haemost (2010) 103(6):1116-27. doi:10.1160/TH09-11-0758

74. Eerenberg ES, Kamphuisen PW, Sijpkens MK, Meijers JC, Buller HR, Levi M. Reversal of rivaroxaban and dabigatran by prothrombin complex concentrate: a randomized, placebo-controlled, crossover study in healthy subjects. Circulation (2011) 124(14):1573-9. doi:10.1161/ CIRCULATIONAHA.111.029017

75. Siegal DM, Cuker A. Reversal of novel oral anticoagulants in patients with major bleeding. J Thromb Thrombolysis (2013) 35(3):391-8. doi:10.1007/ s11239-013-0885-0

76. Pollack CV Jr, Reilly PA, Eikelboom J, Glund S, Verhamme P, Bernstein RA, et al. Idarucizumab for dabigatran reversal. NEngl J Med (2015) 373(6):511-20. doi:10.1056/NEJMoa1502000

77. Patel MR, Mahaffey KW, Garg J, Pan G, Singer DE, Hacke W, et al. Rivaroxaban versus warfarin in nonvalvular atrial fibrillation. $N$ Engl J Med (2011) 365(10):883-91. doi:10.1056/NEJMoa1009638

78. Halvorsen S, Atar D, Yang H, De Caterina R, Erol C, Garcia D, et al. Efficacy and safety of apixaban compared with warfarin according to age for stroke prevention in atrial fibrillation: observations from the ARISTOTLE trial. Eur Heart J (2014) 35(28):1864-72. doi:10.1093/eurheartj/ehu046

79. Baumann Kreuziger LM, Keenan JC, Morton CT, Dries DJ. Management of the bleeding patient receiving new oral anticoagulants: a role for prothrombin complex concentrates. Biomed Res Int (2014) 2014:583794. doi:10.1155/2014/583794

80. Lazo-Langner A, Lang ES, Douketis J. Clinical review: clinical management of new oral anticoagulants: a structured review with emphasis on the reversal of bleeding complications. Crit Care (2013) 17(3):230. doi:10.1186/ cc12592 
81. Ansell JE. Universal, class-specific and drug-specific reversal agents for the new oral anticoagulants. J Thromb Thrombolysis (2016) 41(2):248-52. doi:10.1007/s11239-015-1288-1

82. Siegal DM, Curnutte JT, Connolly SJ, Lu G, Conley PB, Wiens BL, et al. Andexanet alfa for the reversal of factor Xa inhibitor activity. $N$ Engl J Med (2015) 373(25):2413-24. doi:10.1056/NEJMoa1510991

83. Connolly SJ, Milling TJ Jr, Eikelboom JW, Gibson CM, Curnutte JT, Gold A, et al. Andexanet alfa for acute major bleeding associated with factor Xa inhibitors. N Engl J Med (2016) 375(12):1131-41. doi:10.1056/NEJMoa1607887

84. Ansell JE, Bakhru SH, Laulicht BE, Steiner SS, Grosso M, Brown K, et al. Use of PER977 to reverse the anticoagulant effect of edoxaban. N Engl J Med (2014) 371(22):2141-2. doi:10.1056/NEJMc1411800

85. Kaatz S, Kouides PA, Garcia DA, Spyropolous AC, Crowther M, Douketis JD, et al. Guidance on the emergent reversal of oral thrombin and factor
Xa inhibitors. Am J Hematol (2012) 87(Suppl 1):S141-5. doi:10.1002/ ajh.23202

Conflict of Interest Statement: The authors declare that the research was conducted in the absence of any commercial or financial relationships that could be construed as a potential conflict of interest.

Copyright (c) 2017 Gulati, Dua and Torbey. This is an open-access article distributed under the terms of the Creative Commons Attribution License (CC BY). The use, distribution or reproduction in other forums is permitted, provided the original author(s) or licensor are credited and that the original publication in this journal is cited, in accordance with accepted academic practice. No use, distribution or reproduction is permitted which does not comply with these terms. 